\title{
Inhibition of Notch signaling induces extensive intussusceptive neo-angiogenesis by recruitment of mononuclear cells
}

\author{
Ivanka Dimova • Ruslan Hlushchuk • Andrew Makanya - Beata Styp-Rekowska • \\ Amalia Ceausu - Stefanie Flueckiger - Sonja Lang - David Semela • \\ Ferdinand Le Noble $\cdot$ Suvro Chatterjee $\cdot$ Valentin Djonov
}

Received: 30 April 2013/Accepted: 13 July 2013/Published online: 24 July 2013

(C) Springer Science+Business Media Dordrecht 2013

\begin{abstract}
Notch is an intercellular signaling pathway related mainly to sprouting neo-angiogenesis. The objective of our study was to evaluate the angiogenic mechanisms involved in the vascular augmentation (sprouting/ intussusception) after Notch inhibition within perfused vascular beds using the chick area vasculosa and MxCreNotch1(lox/lox) mice. In vivo monitoring combined with morphological investigations demonstrated that inhibition of Notch signaling within perfused vascular beds remarkably induced intussusceptive angiogenesis (IA) with resultant dense immature capillary plexuses. The latter were characterized by $40 \%$ increase in vascular density, pericyte detachment, enhanced vessel permeability, as well as recruitment and extravasation of mononuclear cells into the incipient transluminal pillars (quintessence of IA). Combination of Notch inhibition with injection of bone marrow-derived mononuclear cells dramatically enhanced IA with $80 \%$ increase in vascular density and pillar number augmentation by $420 \%$. Additionally, there was
\end{abstract}

Electronic supplementary material The online version of this article (doi:10.1007/s10456-013-9366-5) contains supplementary material, which is available to authorized users.

I. Dimova - R. Hlushchuk - A. Makanya - B. Styp-Rekowska .

A. Ceausu $\cdot$ S. Flueckiger $\cdot$ S. Lang $\cdot$ V. Djonov

Institute of Anatomy, University of Fribourg,

Fribourg, Switzerland

I. Dimova - R. Hlushchuk - A. Makanya - B. Styp-Rekowska

S. Lang $\cdot$ V. Djonov $(\bowtie)$

Institute of Anatomy, University of Bern,

Baltzerstrasse 2, 3000 Bern 9, Switzerland

e-mail: djonov@ana.unibe.ch; valentin.djonov@ana.unibe.ch

A. Ceausu

"Victor Babes" University of Medicine

and Pharmacy, Timisoara, Romania down-regulation of ephrinB2 mRNA levels consequent to Notch inhibition. Inhibition of ephrinB2 or EphB4 signaling induced some pericyte detachment and resulted in upregulation of VEGFRs but with neither an angiogenic response nor recruitment of mononuclear cells. Notably, Tie-2 receptor was down-regulated, and the chemotactic factors SDF-1/CXCR4 were up-regulated only due to the Notch inhibition. Disruption of Notch signaling at the fronts of developing vessels generally results in massive sprouting. On the contrary, in the already existing vascular beds, down-regulation of Notch signaling triggered rapid augmentation of the vasculature predominantly by IA. Notch inhibition disturbed vessel stability and led to pericyte detachment followed by extravasation of mononuclear cells. The mononuclear cells contributed to formation of transluminal pillars with sustained IA resulting in a dense vascular plexus without concomitant vascular remodeling and maturation.

Keywords Angiogenesis - Molecular regulation of intussusceptive angiogenesis · Notch signaling . EphrinB2/EphB4 · SDF-1/CXCR4

\section{S. Flueckiger \\ Institute of Molecular Health Sciences, \\ ETH Zurich, Zurich, Switzerland}

D. Semela

Department of Biomedicine, University Hospital

Basel \& Kantonsspital, St. Gallen, Switzerland

F. Le Noble

Max Delbrück Center for Molecular Medicine, Berlin, Germany

S. Chatterjee

Vascular Biology Lab, AU-KBC Research Centre,

Anna University, MIT Campus, Chennai, India 


\section{Introduction}

Angiogenesis is essential for normal embryonic development and plays a key role in pathological conditions related to tumor growth and ischemic cardiovascular diseases. Angiogenesis involves the formation of new blood vessels from a preexisting vascular plexus, and based on morphological characteristics, two distinct processes have been identified: sprouting angiogenesis and intussusceptive angiogenesis (IA) [1-3]. Sprouting angiogenesis has been well described in the recent literature and involves tip/stalk cell differentiation in the sprout and is tightly controlled by the Notch/Dll4 signaling pathway [4]. Intussusceptive angiogenesis is a specific mode of blood vessel formation by which instead of extraluminally, endothelial cells form intraluminal "sprout like" protrusions resulting in the formation of transluminal endothelial pillars. Successive reshaping and fusion of such pillars "splits" the preexisting segment in two parts, thus resulting in the formation of an additional vessel segment. This results in formation of supplying and draining vessels, pruning of arteries and veins, and finally remodeling of the primitive capillary plexuses. IA is a step process involving intussusceptive microvascular growth, intussusceptive arborization, and intussusceptive remodeling [2, 3, $5,6]$. The processes lead to formation of hierarchically organized and mature vascular networks. Compared to sprouting angiogenesis, intussusception is relatively fast, thus allowing swift vascular adaptation in compromised conditions. In liver regeneration models and in postpneumonectomy alveolar angiogenesis, intussusception has been identified as the predominant mode of growth, and also in extraembryonic vasculatures including the vitelline circulation, intussusception appears to prevail over sprouting [7-9]. Surprisingly, the cellular and molecular regulation of intussusception is less well known, but recent evidence suggests that it might involve components regulated by blood flow and Notch signaling $[6,7]$. Here, we provide evidence showing that Notch regulates intussusception involving interaction with circulating mononuclear cells in developing vascular networks.

The Notch signaling pathway is evolutionary conserved and plays an important role in cell fate specification and differentiation. The Notch pathway is activated after the Notch receptor binds one of its ligands from Delta and Serrate families, which are expressed by neighboring cells [10]. Notch receptors are single Type I transmembrane proteins located on the cell surface, which interact with ligands expressed on the adjacent cells. It leads to splitting of the receptor by TACE and $\gamma$-secretase and subsequent translocation of its intracellular portion (NICD) into the nucleus. The subsequent interaction with RBP-Jk/CBF-1 protein complex results in expression of genes normally silent in absence of Notch signal such as basic helix-loophelix genes Hes 1, 5, 7 and Hesr/Hey 1, 2, L. In mice, loss and gain of function studies for Notch receptors and Notch ligands including D114/Jag1 and D111 has shown that Notch signaling is essential for normal arterial-venous differentiation and remodeling and for angiogenic sprouting [1114]. In angiogenic sprouts, Dll4/Notch signaling acts as a negative regulator of endothelial tip cell differentiation. Dll4 expressed by endothelial tip cells, activates Notch receptors in stalk cells, resulting in the suppression of VEGFR2, and up-regulation of VEGFR1, a feedback mechanism essential for maintaining adequate tip/stalk cell balance. Gerhardt et al. demonstrated that during sprouting angiogenesis, endothelial cells compete for the leading tip position, and it is dependent not on the absolute but on the relative VEGFR levels between cells. The cells expressing less VEGFR1 or more VEGFR2 have high probability to be found at the tip position, and VEGFR level-mediated competition is strictly Notch dependent [4]. In addition to negative effects on sprouting, Notch signaling has also been shown to have effects on stabilization of vasculature and vessel remodeling [15-19].

Among the complex angiogenic processes regulated by Notch signaling, interactions between endothelial cells and mural cells (pericytes and vascular smooth muscle cells) have recently come into focus as central processes in vascular formation, stabilization, remodeling, and function [20-22]. Up-regulation of Notch signaling in mural cells induces expression of smooth muscle cell (SMC) marker genes, contributes to vessel stabilization and finally to formation of robust and mature vascular networks [23]. EphrinB2/EphB4 signaling is essential for managing the adhesion/repulsion processes, intercellular contacts, and cell migration as well [24, 25]. Functional and molecular analyses show that ephrinB2 is a direct target of Notch signaling [26-28], and it is plausible that they both contribute to vessel maturation and maintenance.

Recently, several groups have found that blockade of Notch signaling leads to disorganized and unproductive endothelial growth, which results in tumor regression [2931]. Similarly, DLL4 inhibition causes formation of a disorganized capillary network in ischemic muscles [32]. Notch inhibition induces deregulated endothelial sprouting and proliferation, independently of VEGFR2, in mouse retina as well [33]. Notch signaling has been mostly related to sprouting neo-angiogenesis. It is obvious that in nonvascularized tissues, especially in non-perfused fronts of developing vessels, for example, in vitro experiments, and in expanding retinal vessels, inhibition of Notch results in extensive formation of capillary sprouts.

Surprisingly, within liver vasculature, it has been shown that Notch1 knockout (KO) mice develop portal 
hypertension and nodular regenerative hyperplasia through sinusoidal remodeling by intussusceptive angiogenesis [7].

Evaluation of the embryonic vascular pattern in the literature indicates that intussusceptive angiogenesis is most likely "locked" in the "on" position (intussusceptive microvascular growth) after Notch inhibition resulting in repetitive pillar formation with no subsequent remodeling or maturation.

In this study, using the chick area vasculosa and a mouse model of Notch inhibition, we have demonstrated that in already existing vascular beds, disruption of Notch signaling triggers rapid augmentation of the vasculature predominantly by intussusceptive angiogenesis. The process is characterized by pericyte detachment and extravasation of mononuclear cells. The latter cells contribute to formation of transluminal pillars. The sustained IA results in a very dense vascular plexus but without the usual concomitant vascular remodeling or maturation. We have studied potential molecular mediators of Notch signaling as well.

\section{Methods}

\section{Animals}

Fertilized white leghorn eggs were obtained from commercial breeders (Fribourg, Switzerland). The eggs were incubated in-shell for 3 days at $37^{\circ} \mathrm{C}$ in humidified $(65 \%)$ atmosphere, containing 1-2\% $\mathrm{CO}_{2}$. The eggs were opened on day 3 and further incubated at the same conditions using shell-free method [2] in petri dishes (Corning Incorporated, Corning, NY, USA). The samples were divided into a control group (Co) and groups of inhibition (I). There were at least six chicken embryos investigated in each group.

MxCre Notch1(lox/lox) mice on a C57B1/6 background carry the Cre-recombinase under the murine Mx1 promoter. To induce recombination, $300 \mu \mathrm{g}$ of polyinosinicpolycytidylic acid (pIpC) (InvivoGen, San Diego, CA, USA) was injected intraperitoneally in 4-week-old mice at days 0,3 , and 6 , resulting in efficient deletion of Notch 1 in the liver already after 1 day. Notch1 deletion was consistent in liver sinusoidal endothelial cells (LSECs) and hepatocytes during the whole observation period.

\section{Reagents}

The $\gamma$-secretase inhibitor 1 (GSI-1) (Calbiochem, Switzerland) is a potent and selective inhibitor of the $\gamma$ secretase complex. The drug with a concentration of $10 \mu \mathrm{g} / \mu \mathrm{l}$ was dissolved in phosphate-buffered saline (PBS), and $2 \mu \mathrm{g}$ of the test solution was applied per quadrant (corresponded to a dose of $80 \mathrm{mg} / \mathrm{kg}$ ). Control samples of the area vasculosa from the same time points and with the same size as GSI-treated ones were treated with equal volumes of PBS. To block EphB4 forward signaling, we used NVP-BHG712, a novel small molecular weight inhibitor designed to block EphB4 phosphorylation (Novartis Institutes for BioMedical Research, Basel, Switzerland). Successful blocking was previously determined by evaluation of EphB4 phosphorylation, and the effective dose was 50-100 mg/kg [34]. Bioactivity of ephrinB2 was neutralized with anti-ephrinB2 antibody (Neuromics, Edina, MN 55439), and presence of the protein was detected by immunohistochemistry. After testing different doses, the successful neutralization was attained at the dose of $40 \mathrm{mg} / \mathrm{kg}$.

RNA isolation and real-time reverse transcription PCR

Total RNA was extracted from Notch1 KO mouse and control livers and from the treated lower right quadrant of the area vasculosa, after inhibitions and also from non-inhibited samples, by using RNeasy Mini kit (Qiagen, Basel, Switzerland). The RNA concentrations were determined spectrophotometrically. cDNA was synthesized by reverse transcription $\left(1 \mathrm{~h}\right.$ at $37^{\circ} \mathrm{C}$ ) using $2 \mu \mathrm{g}$ of total RNA, $1 \mu \mathrm{g}$ of the oligo(dT) primers, and $4 \mathrm{U}$ of ImPromp-II reverse transcriptase (Promega, Wallisellen, Switzerland). cDNA concentrations were then determined using the PicoGreen dsDNA quantification reagent (Invitrogen, Basel, Switzerland). The following primer/probe kits were purchased from Qiagen: 1) Chicken QuantiTest Primer Assay DLL4 (QT0065 6936), Notch2 (QT01504986), Hes5 (QT00630406), ephrinB2 (QT00591794), KDR2 (QT01140244), PCNA (QT00588952), and caspase-3 (QT00588952), VEGFR1 (Flt1) (QT00595987), SDF-1 (CXCL12) (QT01139026), CXCR4 (QT00590128), Tie-2 (TEK) (QT00685629); 2) Mouse QuantiTest Primer Assay Mm_Cxcl12(SDF-1)_1_SG (QT00161112), and Mm_ Cxcr4_1_SG(QT00249305). Quantitative PCR was performed using real-time PCR (R Corbett Research RG-6000). The foldchange expression levels of cDNA were determined from the $\Delta \mathrm{Ct}$ values obtained as compared to $\Delta \mathrm{Ct}$ values of control samples. In our experiment, we used GAPDH (QT00588973) and ACTB (QT00600614) as housekeeping genes.

\section{Morphometry}

Evaluation of vascular parameters was accomplished with Tem Imaging Platform (iTEM) software. Micrographs were obtained from normally developing area vasculosa in order to acquire baseline data and a normal growth curve. From the experimental group, micrographs were taken from inhibited samples at time points 6,12 , and $24 \mathrm{~h}$. The arterial tree of the lower right quadrant was traced in a user-driven way. Subsequently, the arterial tree thus 
obtained was analyzed with the iTEM software to determine vascular length and number of branching points.

The visualization of microvasculature was done by injection of $50 \mu \mathrm{l}$ of $10 \%$ FITC-Dextran $2000 \mathrm{kDa}$ (FD2000S, Sigma-Aldrich, Germany) in $0.9 \% \mathrm{NaCl}$ solution, prior to inspection in an epifluorescence microscope (Polyvar-Reichert, Glattbrugg, Switzerland) equipped with a Canon 5D Mark II camera for both video recording and taking still images. The still images and video sequences of at least 4 fields of view were taken per application site for further quantitative evaluation. Microvascular density and pillar numbers were evaluated using analySIS Software 5.0 (Soft Imaging System, Muenster, Germany).

\section{Transmission electron microscopy}

The samples obtained from the area vasculosa and PBS controls harvested at different time points were immersionfixed in $2.5 \%$ glutaraldehyde solution buffered with $0.03 \mathrm{M}$ potassium phosphate $(\mathrm{pH} \mathrm{7.4,} 370 \mathrm{mOsm})$. The livers of Notch1 $\mathrm{KO}$ and wild-type mice were perfused with fixative [ $2.5 \%$ glutaraldehyde in $0.1 \mathrm{~mol} / \mathrm{L}$ cacodylate buffer $(\mathrm{pH} 7.4,350 \mathrm{mOsm})]$. Then, the liver was excised, cut into small pieces, and immersed in the same fixative.

All samples were then postfixed in $1 \%$ OsO4 (buffered with $0.1 \mathrm{M}$ sodium cacodylate- $\mathrm{pH} \quad 7.4,370 \mathrm{mOsm}$ ), dehydrated in ascending concentrations of ethanol, and embedded in epoxy resin. For light microscopy, $1-\mu \mathrm{m}$-thick sections were prepared using glass knives and stained with toluidine blue. For transmission electron microscopy, 80-90-nm-thick sections were prepared and mounted on copper grids coated with Formvar (polyvinyl formal; Fluka, Buchs, Switzerland). They were stained with lead citrate and uranyl acetate prior to viewing in a Philips EM 400 electron microscope.

\section{Vascular casting}

Vascular casts were prepared as previously described [35]. Briefly, CAM vasculature/the vasculature of the murine liver were perfused with a freshly prepared solution of Mercox ${ }^{\circledR}$ (Vilene Company, Japan) containing $0.1 \mathrm{~mL}$ of accelerator per $5 \mathrm{~mL}$ of resin. One hour after perfusion, the CAM were transferred to $7.5 \%$ potassium hydroxide for digestion of tissue, which was effected over a course of 2-3 weeks. After washing, the casts were dehydrated in ethanol and dried in a vacuum desiccator. The samples were then sputtered with gold to a thickness of $10 \mathrm{~nm}$ and examined in a Philips XL-30 SFEG scanning electron microscope.
Three-dimensional reconstruction from serial semithin sections

Images of serial semithin sections showing sites of interest were taken. The 3D stack of images obtained was aligned and further processed using Imaris Software (Bitplane Scientific Software, Zurich, Switzerland). The 3D surface at the outer border of the vascular lumen was generated (red), and the volume corresponding to the cells invading the pillar was presented in green.

\section{Western blot analysis}

Treated and control samples of the area vasculosa at different time points were pooled (at least 5 embryos in each pool), collected, and homogenized in lysis buffer containing protease inhibitors (Roche, Switzerland). Protein concentration was determined, and SDS-PAGE was performed with $30 \mu \mathrm{g}$ of extracted proteins. Samples were run on a gel and transferred onto polyvinylidene fluoride membranes. Membranes were blocked in blocking buffer (5\% nonfat dry milk in TBS, $0.1 \%$ Tween 20 ) and incubated overnight at $4{ }^{\circ} \mathrm{C}$ with primary anti- $\alpha$ SMA antibody.

In vivo permeability assay

Hoechst dye (Sigma-Aldrich, Buchs, Switzerland), $0.4 \%$ diluted in DPBS, was intravenously injected in chick area vasculosa. After $20 \mathrm{~min}$, FITC-conjugated lectin (SigmaAldrich, L9381; $10 \mu \mathrm{g}$ in $10 \mu \mathrm{l}$ volume per treated area) was intravenously injected to visualize endothelial cells, and after $10 \mathrm{~min}$ of circulation, the treated area vasculosa was removed and prepared for cryosectioning. Sections were air-dried overnight, acetone-fixed, embedded in Mowiol, and immediately analyzed by fluorescence microscopy (Leica MZ16FA microscope connected to a Leica DFC320 Digital Camera with the ThumbsPlus $7 \times$ software).

\section{Mononuclear cell counting}

The serial sections were viewed and images captured at magnification $40 \times$ using a light microscope (Leica, Leitz DM), equipped with Leica DFC480 camera. At least 10 images were taken per sample for further quantitative evaluation, and at least 10 samples for each application were evaluated. The total number of adherent/extravasated mononuclear cells per vessel circumference was assessed using analySIS Software 5.0 (Soft Imaging System, Muenster, Germany) by means of user-driven skeletonization of the vascular circumference. 
Bone marrow mononuclear cells isolation and labeling

To isolate bone marrow mononuclear cells, 4-6-week-old male BALB/c mice (BALB/cByJ, Charles River Laboratories, France) were sacrificed and their femur and tibia collected in DMEM (Gibco) supplemented with $10 \%$ FBS (fetal bovine serum, Sigma-Aldrich, Germany). Bone marrow was flushed-off using PBS with $2 \% \mathrm{FBS}$ and collected in a tube with $2 \mathrm{mM}$ EDTA/PBS. The solution was then diluted with $10 \times$ volume RPMI1640 containing $0.02 \%$ collagenase $\mathrm{B}$ and $100 \mathrm{U} / \mathrm{ml}$ DNase and agitated gently at room temperature for $45 \mathrm{~min}$. The cells were passed through $30 \mu \mathrm{m}$ nylon mesh, centrifuged, and resuspended in PBS. The cell suspension was gently and slowly added onto a tube containing the same volume of Histopaque-1077 (Sigma-Aldrich, Cat. 10771). After 30-min centrifugation, the white cellular ring floating over the Ficoll phase (mononuclear cells) was collected and transferred into a new tube, filled with $1 \times$ PBS, and centrifuged to wash. The cells were warmed up (in DMEM) for $20 \mathrm{~min}$ at $37{ }^{\circ} \mathrm{C}$. TAMRA stock solution (TAMRA from Sigma Cat. No 1171, solved in N,N-dimethylformamide from Sigma Cat. No 539465) was added to the cells to get a concentration of $200 \mu \mathrm{mol} / \mathrm{l}$. Thereafter, the cells were incubated with TAMRA for 20 min., washed twice, resuspended in an appropriate amount of medium (in order to have $2-4 \times 10^{5}$ cells for each injection), and mixed with $15 \%$ FITC in a ratio $3: 1$.

\section{Statistical analysis}

Probability associated with a Student's paired $t$ test, with a two-tailed distribution, was considered in a given $p$ value for each comparison.

\section{Results}

Expression changes in genes related to Notch function

Using the chick area vasculosa (Hamburger and Hamilton stages HH23-HH30), we performed expression analysis for Notch2, DLL4, and ephrinB2 in normal development (Fig. 1a, $n=10$ for each time point and condition). Starting from the embryonic day 4 (E4, time point 0 ), we detected a peak of Notch 2 expression $6 \mathrm{~h}$ later and applied the inhibitor before the peak time. To verify successful blocking of Notch signaling by differential doses and types
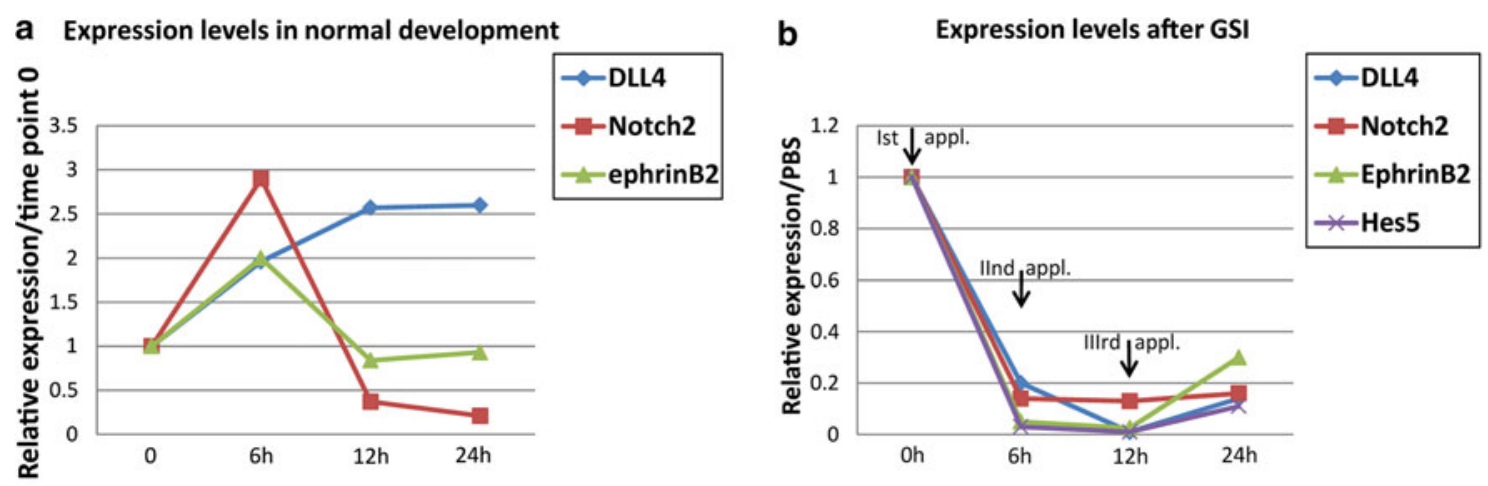
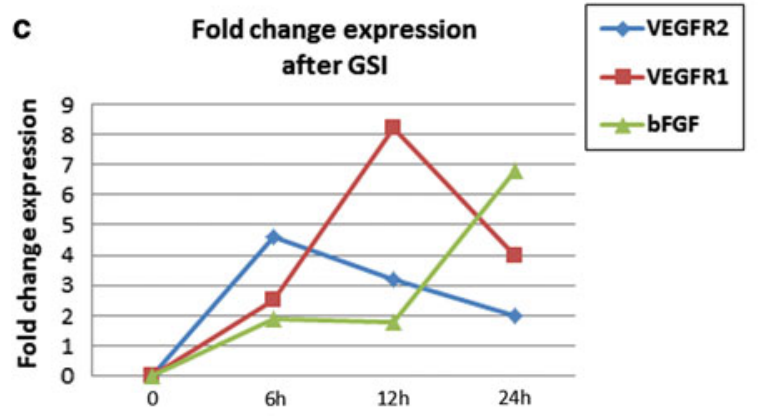

d

d

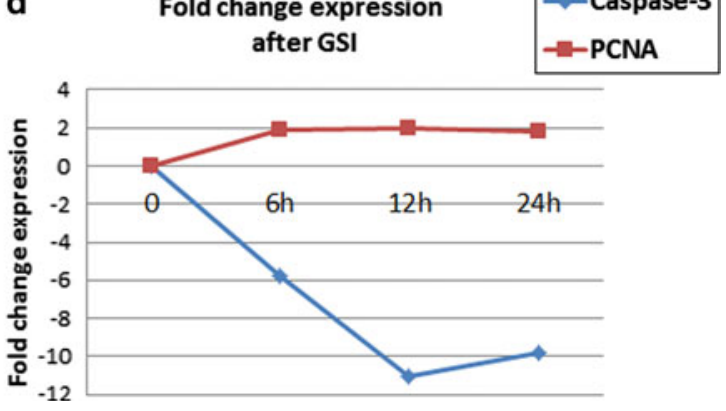

Fig. 1 Expression levels of genes related to Notch function in the chick area vasculosa after Notch inhibition by GSI. a Time course of DLL4, Notch2, and ephrinB2 expression during normal development of the chick area vasculosa. b A significant decrease in the expression levels of DLL4, Notch2, ephrinB2, and Hes5 is achieved after three applications of GSI $(2 \mu \mathrm{g}$ at 0,6 and $12 \mathrm{~h})$. c Up-regulation of classical angiogenic factors VEGFR1, VEGFR2, and bFGF under GSI treatment. d Cell turnover estimated by expression levels of caspase-3 and PCNA after Notch inhibition 
a
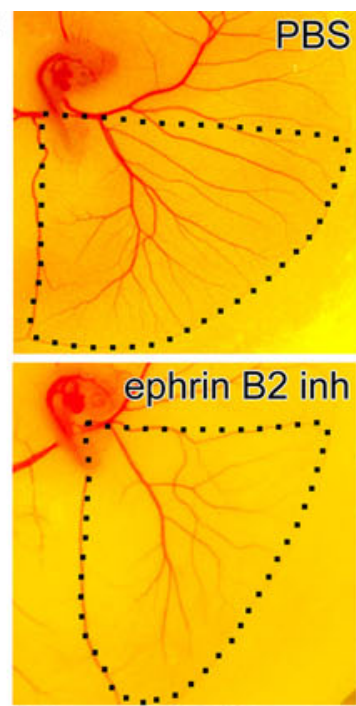

b
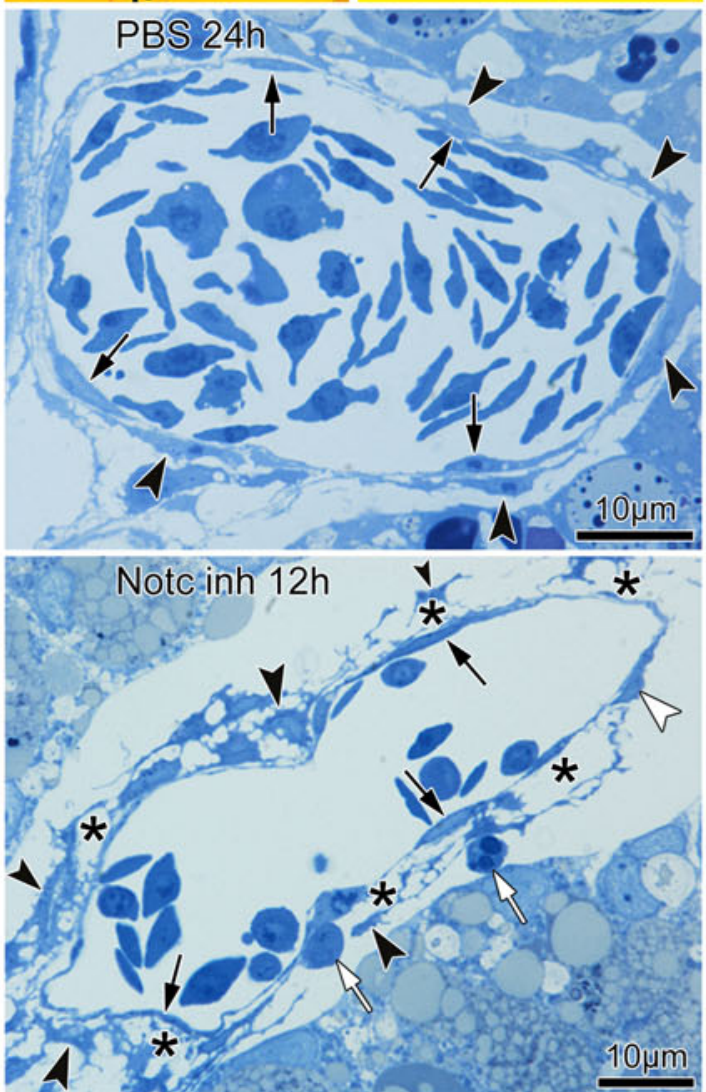

C

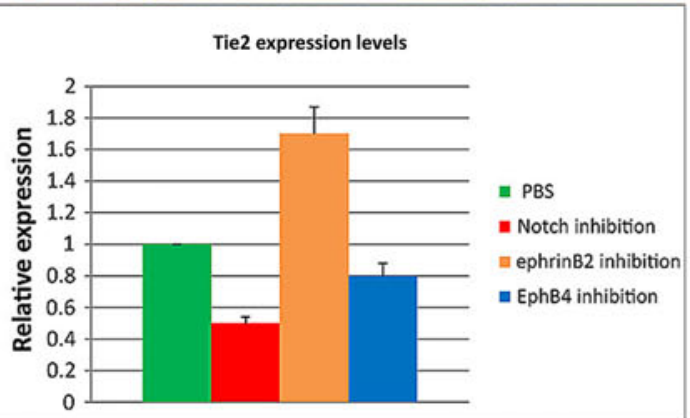

Absolute surface of treated area

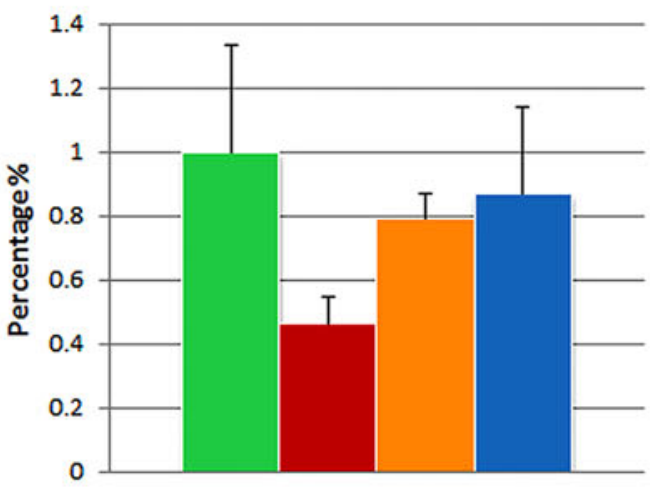

" PBS $\mid$ Notch inhibition $=$ ephrinB2 inhibition $=$ EphB4 inhibition
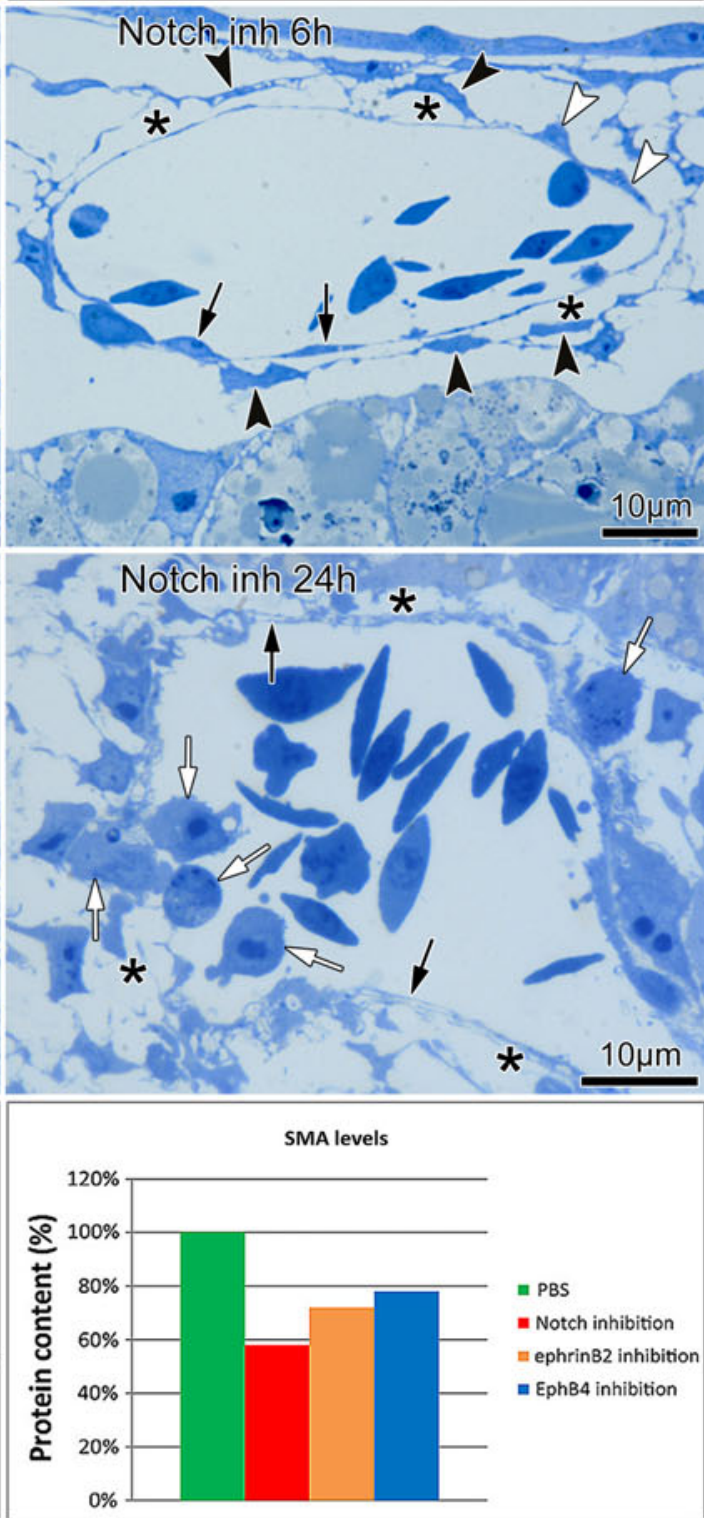
4 Fig. 2 Disturbed vessel maturation after inhibition of the Notch signaling. a Overview of the lower right quadrant of the area vasculosa $24 \mathrm{~h}$ after different treatments. Absolute surface area of the treated quadrant decreased after all inhibitions but is most noticeable after Notch inhibition $(p<0.04, n=12)$. b Semithin sections showing disrupted vascular wall integrity after Notch inhibition. Pericytes (black arrowheads) cover and closely adhere to the endothelial cells (black arrows) in the controls (PBS). GSI treatment caused detachment of the pericytes at $6 \mathrm{~h}$ and gap formation between them and the endothelium (asterisks). Non-detached pericytes are indicated by white arrowheads. By time point $12 \mathrm{~h}$, the gaps appear larger; the pericytes retract and become star-shaped. The first mononuclear cells (white arrows) are detectable in the periendothelial space. By time point $24 \mathrm{~h}$, the vascular wall structure appears disorganized with very thin and partially disrupted endothelium. The endothelial gaps are used as an exit for the extravasating mononuclear cells. c Expression of Tie-2 receptor and SMA protein levels after different treatments

of application of the $\gamma$-secretase inhibitor (GSI), we monitored expression levels of Notch2, DLL4, and the Notch target Hes5 in parallel with controls. The most efficient blocking was reached by doses of $2 \mu \mathrm{g}$ of GSI per lower right quadrant of the area vasculosa (corresponding to $40-80 \mathrm{mg} / \mathrm{kg}$ ). Chronic blockade was achieved after double and triple application of GSI. The mRNA levels of Hes5, DLL4, and ephrinB2 were significantly lower in all inhibited samples than in the controls (Fig. 1b).

Looking for potential molecular targets of Notch inhibition, we investigated the expression changes in some of the classical factors of apoptosis, proliferation, and angiogenesis. VEGFR2 and especially VEGFR1 were up-regulated after Notch inhibition, and increase in expression levels of bFGF was detected as well (Fig. 1c). The expression of apoptosis marker caspase-3 consistently decreased during the time course of GSI application (Fig. 1d). The proliferation marker PCNA slightly increased its expression levels (Fig. 1d).

Notch inhibition results in pericyte detachment, extravasation of mononuclear cells and formation of transvascular tissue pillars

The significant decrease in ephrinB2 mRNA levels after Notch inhibition prompted us to investigate the angiogenic effects upon blockade of the forward and reverse ephrinB2/ EphB4 signaling. The absolute surface area of the treated lower right quadrant of the area vasculosa was considerably reduced after GSI application in comparison with the controls (by $54 \%$ ) and with ephrinB2 and EphB4 inhibitions (Fig. 2a). Morphological evaluation of semithin sections at higher magnification revealed disrupted vascular walls after GSI treatment (Fig. 2b). In all samples treated with GSI, progressive pericyte detachment from endothelial cells was observed in the first few hours, so that after $6 \mathrm{~h}$, large gaps between endothelial cells and pericytes were documented. With time, the gaps appeared larger, and by $12 \mathrm{~h}$, the pericytes retracted and reshaped to stellate like cells, and no longer covered the endothelia. Concomitantly, the first mononuclear cell extravasation occurred. At $24 \mathrm{~h}$, the vascular wall structure appeared disorganized, and the morphology was defined by partially disrupted endothelia with retracted pericytes and a multitude of extravasating mononuclear cells passing through the endothelial gaps (Fig. 2b).

Slight disturbance of the contacts between pericytes and endothelia was observed also after inhibition of ephrinB2 and EphB4 (data not shown), but to a much lesser extent compared to the drastic effects occurring after GSI treatment. The resultant morphological disturbance was related to the observed protein expression levels. Western blotting for $\alpha$ SMA revealed around $50 \%$ decreases in this pericyte marker after Notch inhibition and about $25 \%$ reduction after ephrinB2 and EphB4 inhibition (Fig. 2c). Additionally, there was a two-fold Tie-2 down-regulation after Notch inhibition. Tie-2 is a marker associated with vessel stabilization, but was only slightly down-regulated after EphB4 inhibition and up-regulated after ephrinB2 inhibition (Fig. 2c).

The vessel instability resulting from disturbed pericyte alignment prompted us to investigate vessel permeability. Using lectin/Hoechst staining as an in vivo permeability assay (Supplementary Figure 1), we observed much higher permeability after Notch inhibition, which was in accordance with expression levels of $\alpha$ SMA protein and Tie-2 mRNA.

Morphological evaluation by light and transmission electron microscopy revealed extravasation of mononuclear cells already by $6 \mathrm{~h}$ after Notch inhibition (Fig. 3a, b). Such cells participated in subsequent steps of extravasation (attachment to the endothelium, para- or intracellular passage through the endothelium, invasion of the basement membrane followed by perivascular accumulation). The extravasated cells phenotypically resembled stem cell-like cells [41]. Quantitative analyses $24 \mathrm{~h}$ after Notch inhibition demonstrated 6 times more extravasated mononuclear cells as compared to controls and 3-4 times more as compared to ephrinB2 and EphB4 inhibition (Fig. 3a).

To follow and document the fate of the extravasating mononuclear cells, 3D reconstruction of vessels from GSItreated and control samples was undertaken (Fig. 3c). This was based on sections obtained from regions with pillars initially identified under video microscopy (see also Fig. 5). TEM revealed a high number of mononuclear cells attached to the endothelium and later in the vicinity of pillars, stabilizing the pillar core from the both sites, 

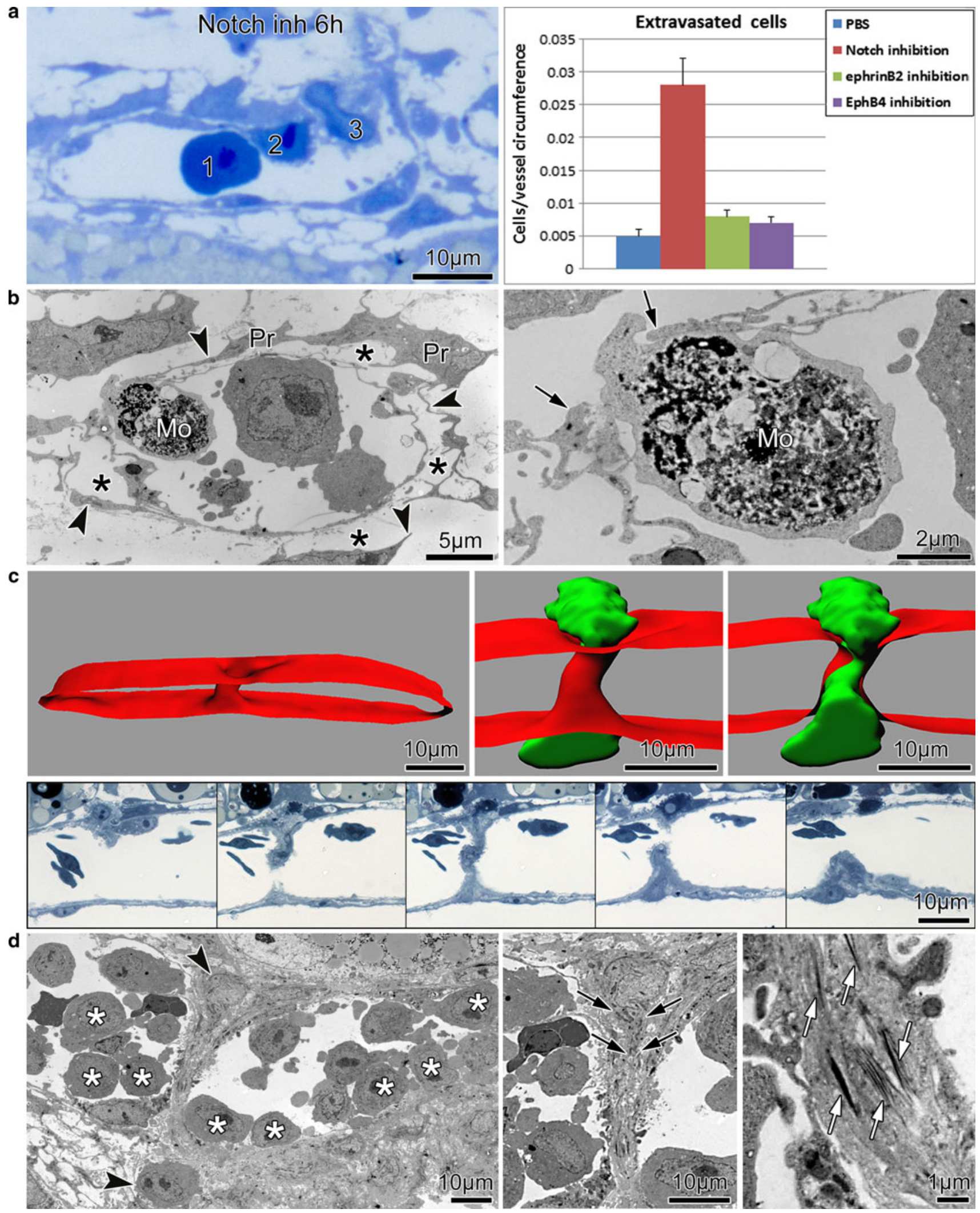

plausibly indicating their participation in pillar formation (Fig. 3d). A closer view revealed the presence of mononuclear cells into the pillar core surrounded by collagen

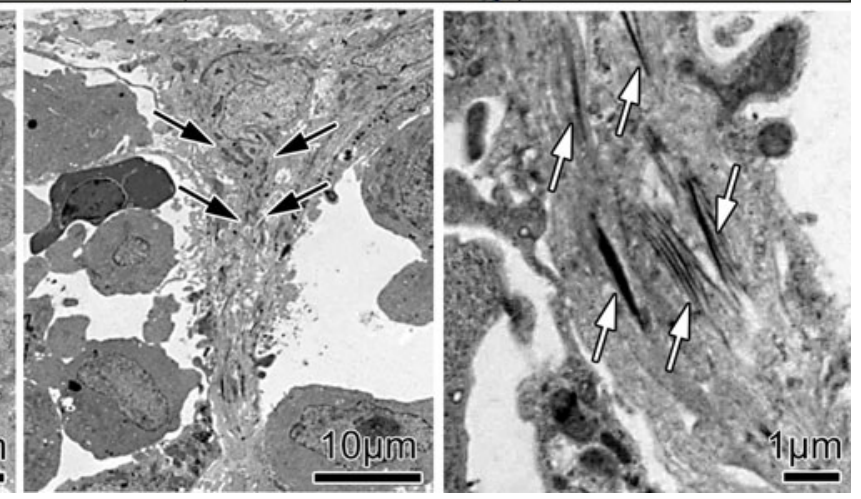

fibers (Fig. 3d). The collagen deposition in the pillar core is quite an early event and seems to be crucial for the mechanical stabilization and resistance to flow. 
4Fig. 3 Extravasation of mononuclear cells after pericyte detachment-contribution to pillar formation. a Different stages of mononuclear cell extravasation $6 \mathrm{~h}$ after GSI treatment of area vasculosa: attachment to the endothelium ( 1 and 2), para- or intracellular passage through the endothelium with invasion of the basement membrane (3). The number of extravasated mononuclear cells after $24 \mathrm{~h}$ was about 6 times higher in Notch-inhibited samples as compared to controls $(p<0.01, n=12)$ and 3-4 times more as compared to ephrinB2 and EphB4 inhibition. b Transmission electron micrographs documented the significantly enlarged periendothelial space (asterisks) bounded by the detached pericytes ( $\mathrm{Pr}$ ) and their protrusions (arrowheads). Extravasating mononuclear cell (Mo) passing through the endothelial gap indicated by arrows. Right micrograph is a part of the left at a higher magnification. $\mathbf{c}$ Pillar reconstruction (3D) of serial semithin sections from GSI-treated area vasculosa (most important sections demonstrated below) revealing the extravasated mononuclear cells (green) in the vicinity of pillars; the vascular wall is indicated in red. d Ultrathin sections revealed a multitude of mononuclear cells attached to the endothelium (asterisks) and two cells (arrowheads) from both sides of the pillar as demonstrated in reconstructed images (c in green). They sent cellular protrusions (double arrows) in the vicinity of the pillar and are most likely responsible for the collagen deposition (open arrows) which contributes to additional stabilization of the pillar and finally resistance to flow. Middle and right micrographs are parts of the left one at a higher magnification

Induction of intussusceptive microvascular growth (pillar formation) after Notch inhibition

The effects of Notch versus EphB4 and ephrinB2 inhibitions on microvasculature were further evaluated by FITCdextran injection in the area vasculosa (Fig. 4a). Notch inhibition resulted in very dense capillary networks but without the classical standard vascular hierarchy. Typical features of intussusceptive microvascular growth, i.e., transluminal tissue pillars were represented by dark dots in the green perfused vessels (correspond to the red pillar in Fig. 3c). Figure $4 \mathrm{~b}$ shows augmentation of microvascular area density. Inhibition of Notch signaling led to increased microvascular density by $37.5 \%$ as compared to control (Fig. 4b). More than three-fold increase in the number of nascent pillars with diameter less than $2.5 \mu \mathrm{m}$ indicated that the preferred angiogenic growth mechanism was intussusception (Fig. 4c).

Vascular casts from the chick area vasculosa (Fig. 5a) and MxCre Notch1(lox/lox) mice (Fig. 5b) indicated profoundly enhanced IA characterized by pillar formation, demonstrated in the cast by tiny holes (correspond to the red pillar in Fig. 3c). This phenomenon confirms the hypothesis that inhibition of Notch signaling induces IA in birds and mammals.

Molecular alterations after blocking of forward and reverse ephrinB2/EphB4 signaling compared to Notch inhibition

The classical proangiogenic factor VEGFA and its main receptors VEGFR2 and VEGFR1 after application of all inhibitors (Fig. 6a) were also examined. Interestingly, VEGFR1 was markedly up-regulated in all treated samples compared to controls with the highest fold-change expression especially after inhibition of ephrinB2 and its receptor EphB4. VEGFR2 was also up-regulated after these two inhibitors but to a lower extent. On the other hand, VEGFA did not show significant changes, following treatment with any of the inhibitors (Fig. 6a).

The stroma-derived factor-1 (SDF-1) and its receptor CXCR4 play a crucial role in the homing of bone marrowderived mononuclear cells and their migration. Interestingly, GSI treatment led to an increase in SDF-1 levels by 1.8 -fold and CXCR4 expression by 1.5 -fold in the area vasculosa compared to controls. In contrast, treatment with the EphB4 inhibitor led to down-regulation of SDF-1 by 2.5 -fold and of CXCR4 by three-fold. After ephrinB2 inhibition, there was almost no change in the transcription levels of these genes (1.1- and 0.9-fold-change expression, respectively) (Fig. 6b).

Additionally, expression analysis for SDF-1 and CXCR4 mRNA levels done in liver samples from MxCre Notch1(lox/lox) mice recorded an increase of 38 and $20 \%$ for SDF-1 and CXCR4, respectively (Fig. 6b).

Increased intussusception in GSI-treated samples after injection of bone marrow-derived mononuclear cells

To test the role of bone marrow cells in the process of intussusception, we isolated bone marrow mononuclear cells (BMCs) from E14 chicken embryos and/or 4-weekold mice, labeled them with a fluorescent cell tracker (TAMRA), and injected them into the inhibited and control samples $3 \mathrm{~h}$ prior to time point $24 \mathrm{~h}$ at which time the samples were visualized by FITC injection (Fig. 7). We observed much more recruitment and extravasation of the labeled BMCs in inhibited samples (Fig. 7b, c) as compared to the controls (Fig. 7a).

In addition, 3-4 $\mathrm{h}$ after BMCs injection, we observed a significant induction of intussusception in the GSI-treated area as we detected high increase in the pillar number (4.2-fold) in inhibited samples as compared to controls (Fig. 8a-c).

The GSI samples with bone marrow injection showed the highest increase in pillar number $(63 \%)$ as compared to GSI samples alone (Fig. 8c). Microvascular density was higher by $80 \%$ in GSI samples compared to controls after bone marrow injection, and it increased by $30 \%$ in GSI samples after bone marrow injection compared to GSI samples alone (Fig. 8c). The effect was local at the site of application of GSI, as is evident from the images, showing treated and contralateral side of the same embryo (Fig. 8a, b). 


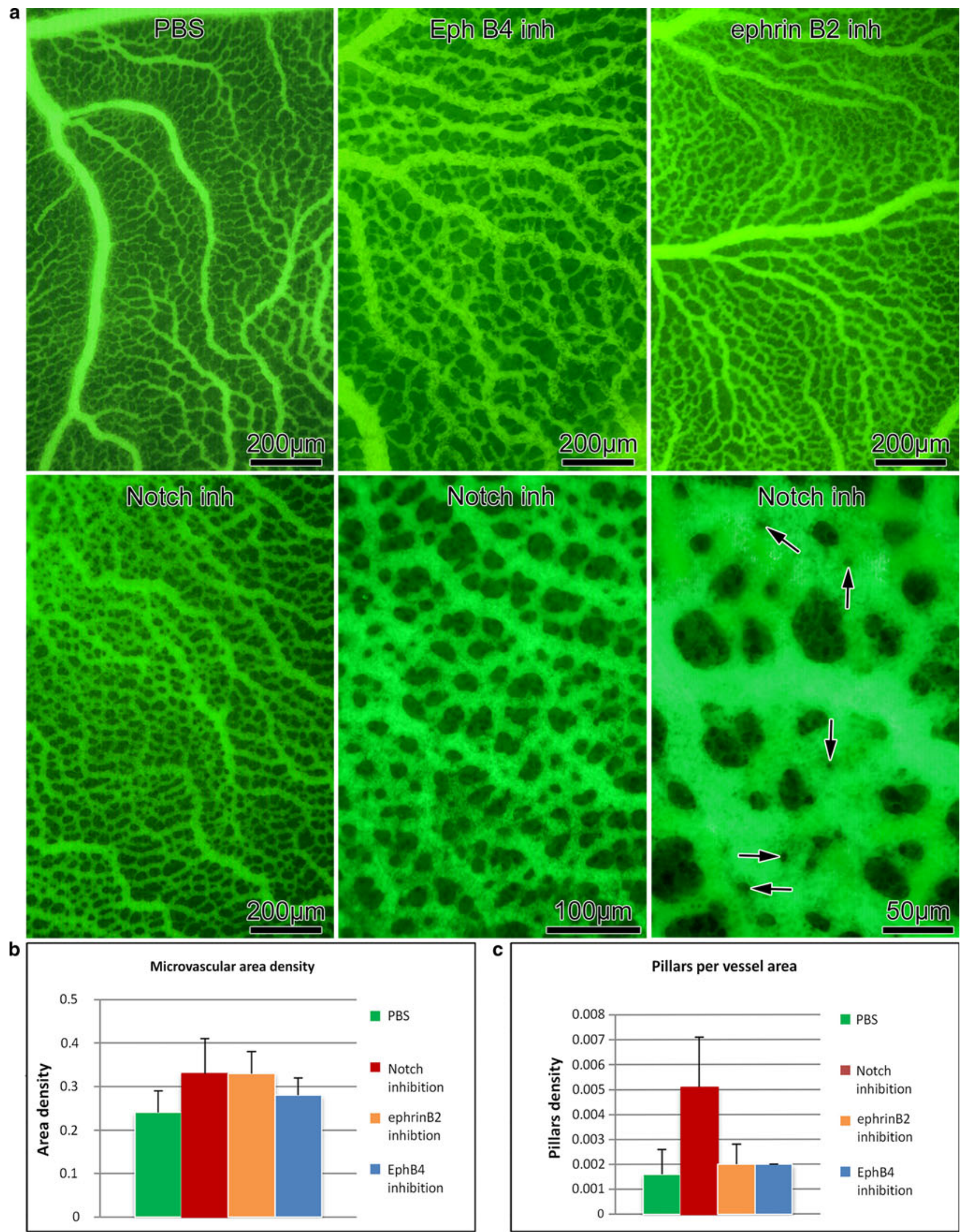


4 Fig. 4 Inhibition of Notch signaling dramatically induces intussusceptive microvascular growth. a The vasculature of chick area vasculosa $24 \mathrm{~h}$ after different inhibitory treatments (application in the left upper corner) visualized by FITC-dextran injection. Notch inhibition represented by different magnifications demonstrated very dense capillary meshwork. Arrows indicate small transluminal tissue pillars represented as dark spots, which are reminiscent of intussusceptive angiogenic growth mode. Please see Fig. $8 \mathrm{~b}$ as comparison to the PBS control treatment at same magnification. b Microvascular area density increases significantly after Notch inhibition $(* p<0.06$, $n=12$ ). c Pillar density estimation demonstrated dramatic augmentation primarily after Notch suppression $(* p<0.07, n=12)$

In contrast to inhibited samples, pillars were only increased by $25 \%$ in control samples after bone marrow injection as compared to control samples without bone marrow injection. No difference was observed in microvascular density of control samples after bone marrow injection compared to control samples without bone marrow injection (Fig. 8c).

\section{Discussion}

Using a genetic approach in mice substantiated by pharmacological studies in developing vascular networks in chicken embryos, we show that Notch is critical for intussusceptive angiogenesis. Within already existing vascular beds (chick area vasculosa and MxCre Notch1(lox/ lox) mice), we demonstrated considerable changes in vascular morphogenesis, resulting in massive induction of intussusception after Notch depletion. The pericytes in both models were widely detached from endothelium, which corresponded to down-regulation of Tie- 2 receptor and reduced protein level of aSMA. The vessel surface was rich in tissue pillars, the hallmarks of intussusceptive angiogenesis. The latter led to increased microvascular density by about $40 \%$ compared to controls; at the same time, the surface area of chick area vasculosa was smaller by about $50 \%$ in comparison with the controls. We observed occasionally sprouting vessels in the model. To our knowledge, this is the first report that within already existing vascular beds, inhibition of Notch signaling induces neo-angiogenesis by intussusception and not by sprouting.

In a recently published study [36], a novel therapeutic antibody against DLL4 promoted vessel formation resulting in a threefold induction in vessel number. This was associated with a concomitant reduction in the percentage of smooth muscle actin (SMA)-positive mural cells. The observed phenotype and the 2D appearance of the blood vessels closely resemble our data in both the chicken and the mouse model. Notch inhibition during developmental angiogenesis, in skeletal muscle and in tumor models caused similar phenotypes, revealing increased vascular density and increased vascular leakage [30-32, 37, 38].
The authors in the latter studies described the resultant vascular pattern as "abnormal vessels" or "excessive, nonproductive angiogenesis." Blocking Notch signaling, they focused mainly on the front of sprouting invasion, which represents developing, non-formed vasculature. Despite the observed significant angiogenic activity under Notch inhibition, the authors mentioned here above nicely documented reduced mural cell coverage. Endothelial protrusions in the vessel lumen and intraluminal vessel occlusions were positive for endothelial markers [38], but the authors failed to attribute this effect to the induced intussusceptive angiogenesis. Careful look at the vascular pattern behind the invading sprouting vessels demonstrated that in already formed vascular bed, Notch inhibition led to IA, which is a complementary mechanism of angiogenesis. The findings described are characteristic features of intussusceptive microvascular growth, which we have documented in the results section by in vivo observation, on semithin serial sections, and in vascular casts.

Al Haj et al. reported formation of a disorganized, poorly-perfused capillary network with leukocyte infiltration and up-regulation of chemo attractant in skeletal muscle after inhibition of endogenous Dll4 by $A d-s D l l 4$. The documented vascular pattern represented a dense capillary plexus expanding by IA. It seems that due to lack of in vivo follow-up, the authors hypothesize that the loops (actually pillars, i.e., IA) were sprout connections [32].

Blocking of Notch signaling in mouse retina also led to significant increase in vascular density [33, 39] with deregulated endothelial growth but without any increase in VEGFR2 levels, the main marker for sprouting [33]. Our previous investigation using VEGF inhibitors in mouse tumor model and kidney regeneration after Thy 1 nephritis indicated that IA occurs in a VEGF independent manner and that the tumor could escape anti-VEGF therapy by switch from sprouting to intussusceptive angiogenesis [40, 41].

Notably, in addition, we revealed extensive extravasation of mononuclear cells, following GSI treatment, and their participation in the formation of tissue pillars was evidently demonstrated. Here, we have revealed that inhibition of Notch signaling disturbs vessel integrity and leads to increased vessel permeability and recruitment of mononuclear cells, which extravasate and accumulate in perivascular spaces. TEM images revealed that extravasated cells were morphologically similar to stem cell-like cells isolated from murine bone marrow [42]. Thereby, we isolated BMCs from chicken and mice and tested their effect in the area vasculosa treated with GSI and PBS. We observed a major effect of the stimulation of intussusception with increase in microvascular area density in Notchinhibited samples by $80 \%$ compared to controls and augmentation of pillar number by $420 \%$. It has been shown 


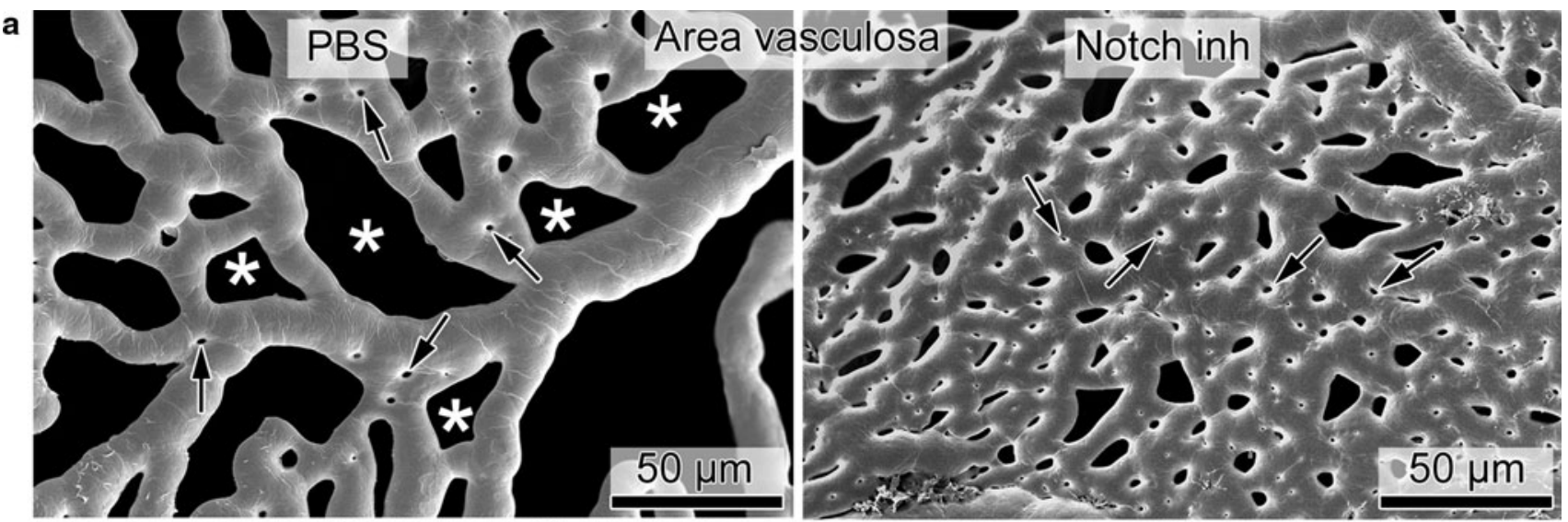

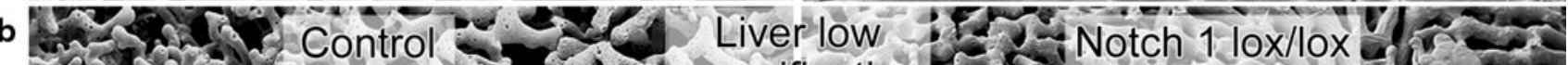

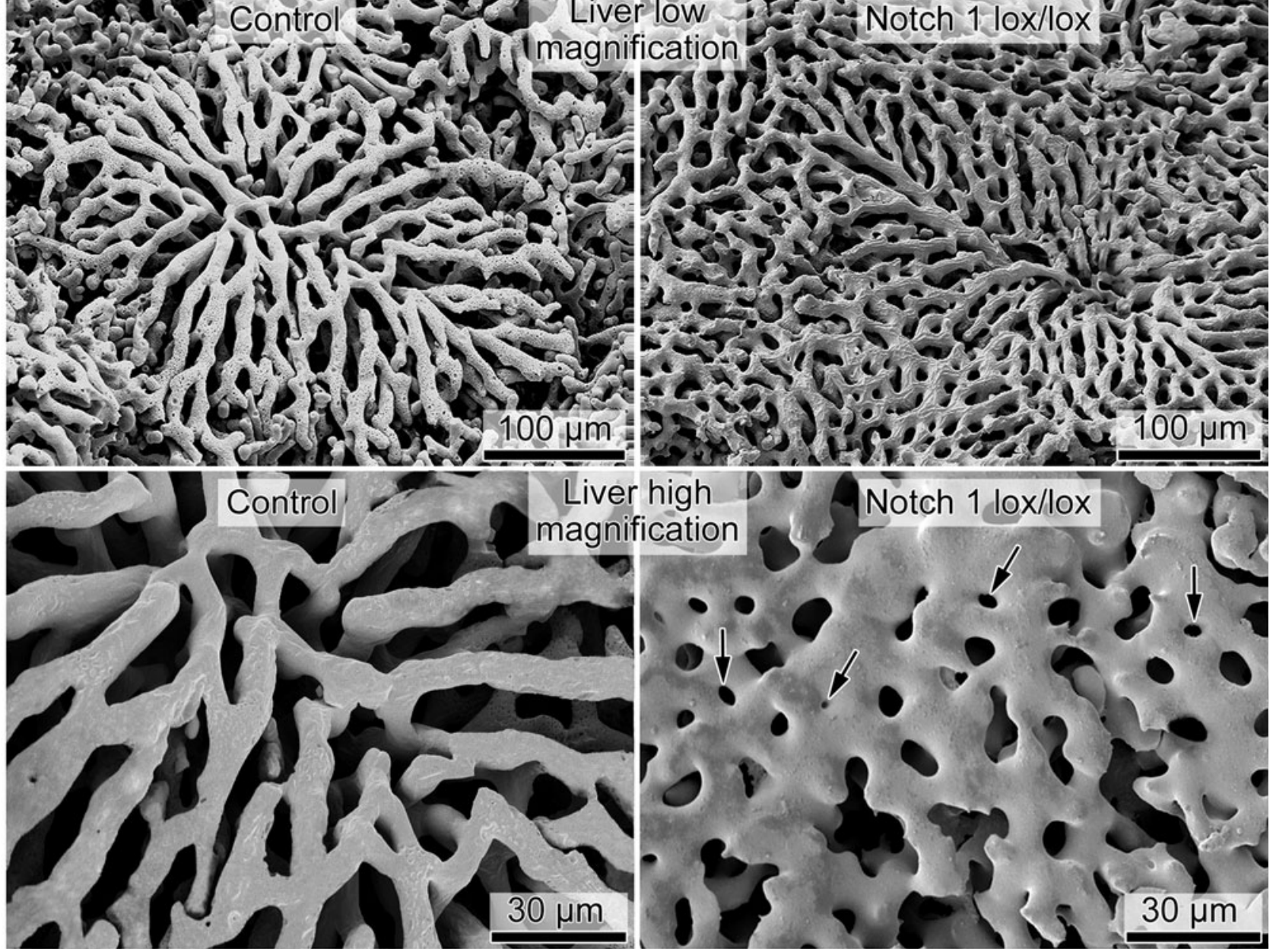

Fig. 5 Recruitment of mononuclear cells contributes to pillar formation, i.e., to induction of IA. a Vascular cast from control area vasculosa revealed standard large vascular loops (asterisks) with occasional pillar formation (arrows). Notch inhibition resulted in a very dense capillary plexus (same magnification) with a multitude of

that treatment of chicken embryos with donor chicken bone marrow cells led to high vessel density after irradiation [43]. Over the last several years, it has been demonstrated that various bone marrow-derived myeloid cells exert pillars, demonstrated in the cast by tiny holes (arrows). b Vascular cast from control mice at low and high magnification revealed normal liver angioarchitecture. Notch down-regulation in the $\mathrm{MxCre}$ Notch(lox/lox) mice induces formation of a dense capillary meshwork due to the pronounced IA characterized by pillar formation (arrows)

proangiogenic activity and contribute to different aspects of angiogenesis [44, 45]. Notch inhibition was connected to inflammatory angiogenesis in situations such as choroidal neovascularization [46]. Here, we show for the first time 

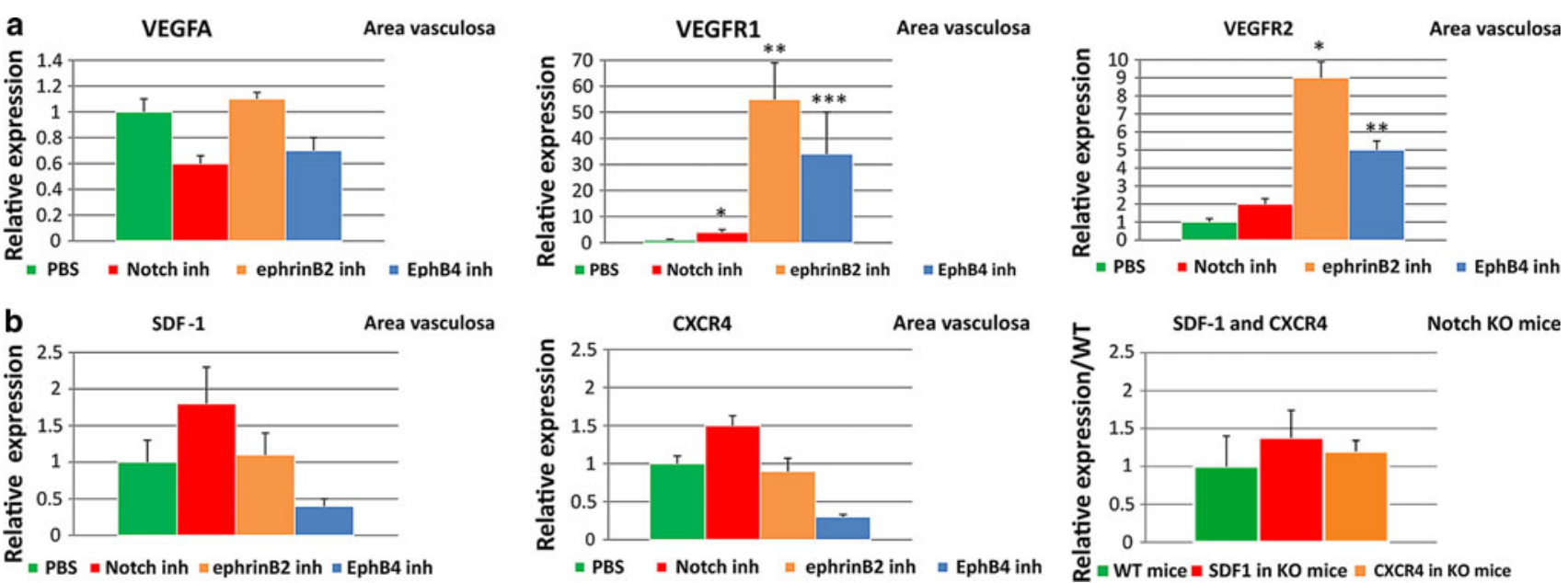

Fig. 6 Changes in expression levels of angiogenic (a) and chemotactic factors (b) after inhibition of Notch, ephrinB2, and EphB4 in the area vasculosa and in MxCre Notch(lox/lox) mice. Area vasculosa: expression levels of VEGFA were slightly down-regulated after Notch and EphB4 inhibition. VEGFR2 was most significantly up-regulated after ephrinB2 $(p<0.03, n=6)$ and EphB4 blockade $(p<0.009, n=6)$. Up-regulation of VEGFR1 in all treated samples most remarkably after ephrinB2 $(p<0.001, n=6)$ and EphB4 $(p<0.02, n=6)$ inhibitions. The chemotactic factor SDF-1 and its receptor CXCR4 were up-regulated (by 78 and $50 \%$, respectively) after Notch inhibition, down-regulated after EphB4 inhibition and did not show any change after ephrinB2 inhibition. In the Notch $\mathrm{KO}$ mice, we detected an increase of 38 and $20 \%$ in expression levels of SDF-1 and CXCR4, respectively
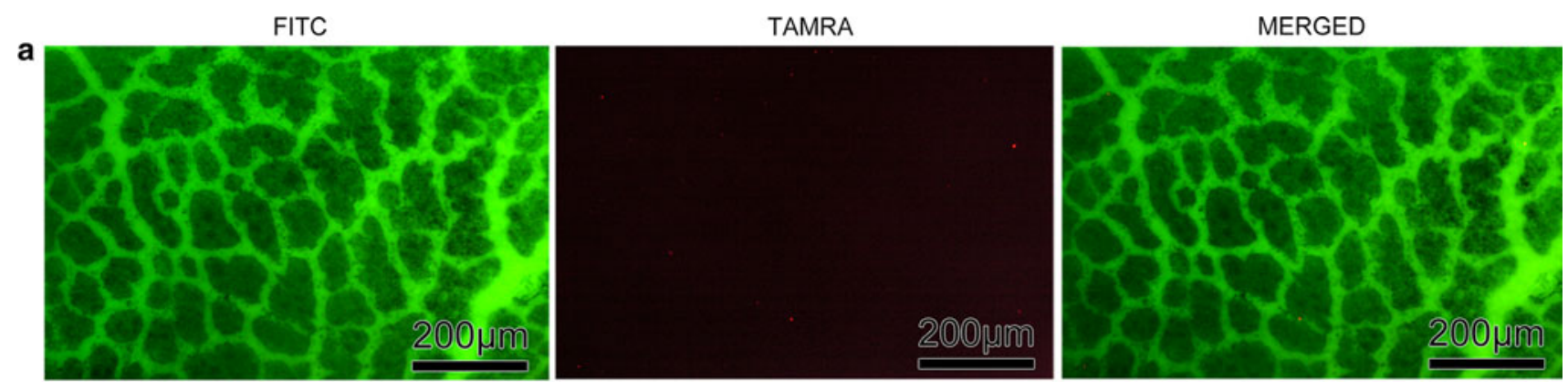

b
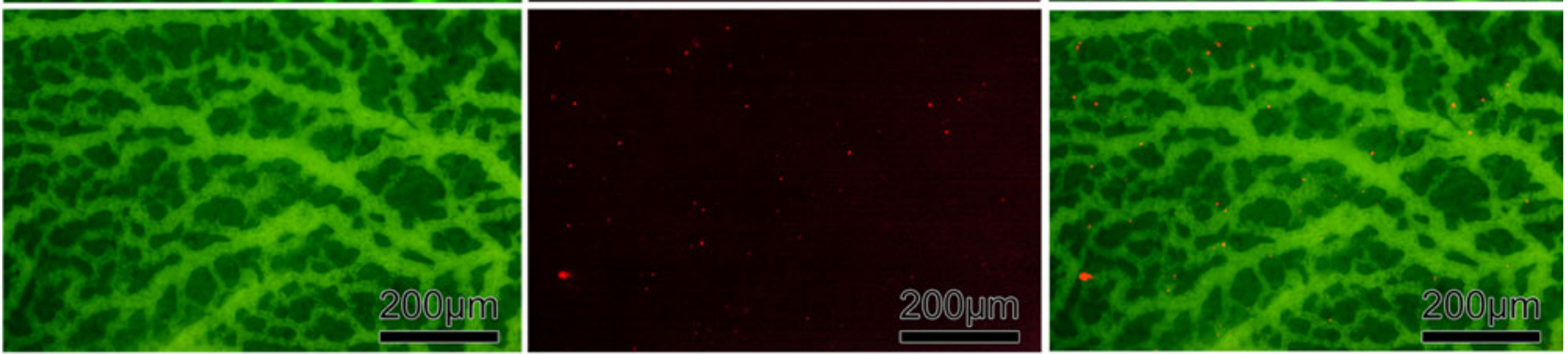

C
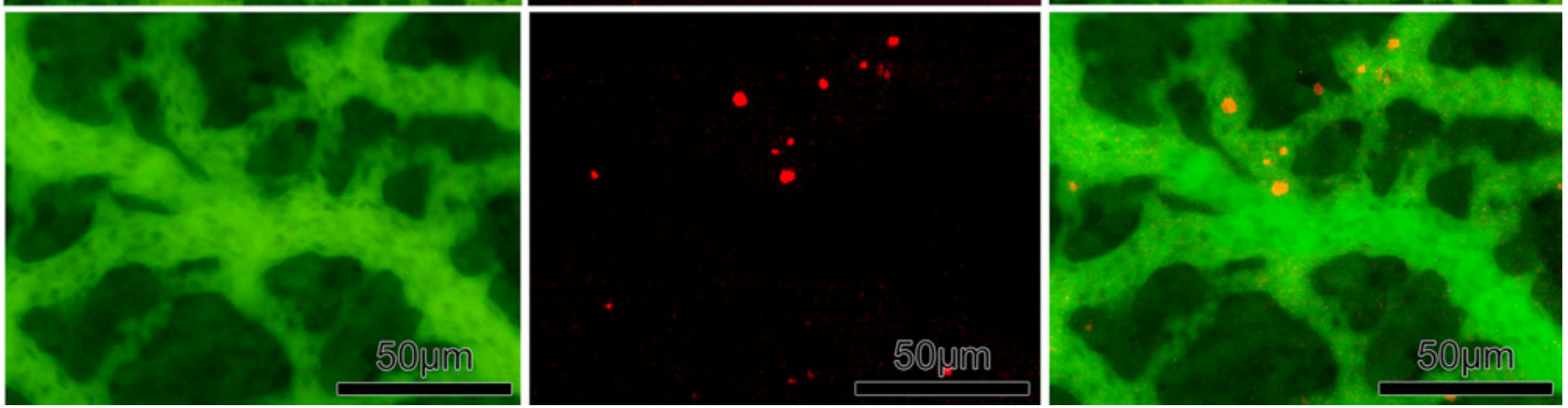

Fig. 7 Injection of labeled bone marrow-derived mononuclear cells (BMCs) in Notch-inhibited and PBS-treated samples of chicken area vasculosa $24 \mathrm{~h}$ after treatment. Accumulation and extravasation of
BMCs (red) was much higher in GSI samples (b) compared to controls (a), $\mathbf{c}$ represents higher magnification of $\mathbf{b}$ 

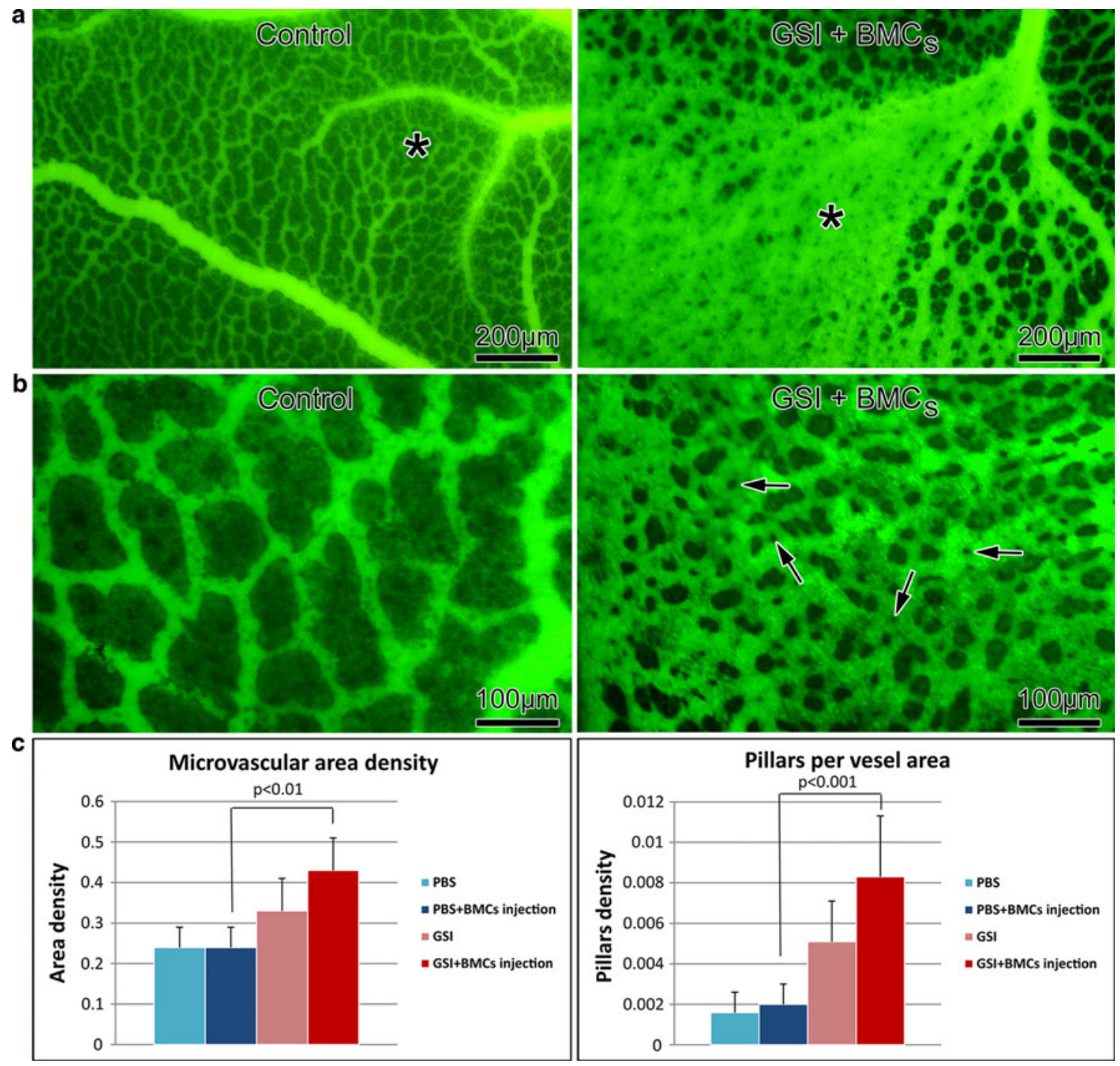

Fig. 8 Injection of BMCs in the area vasculosa after Notch inhibition (application site indicated by asterisk) dramatically induces increase in microvascular density by onset of IA (arrows, b is higher magnification of a). The area surrounding the application site represented normal vascular pattern similar to the one observed in the controls. c Microvascular area density increases significantly by

that BMCs participate in pillar formation after Notch inhibition, a concept which is considerable progress in understanding of intussusceptive angiogenesis.

A number of Notch-related pathways that play a pivotal role in vascular development have been identified so far [47-49]. Some of these, i.e., ephrinB2/EphB4, which are responsible for the organization of cytoskeleton and cell junctions, are good candidates for vessel stability. We investigated vascular morphogenesis in our model upon blocking of both forward and reverse ephrinB2/EphB4, taking into account the complexity and distinct effects of this bidirectional signaling. Our study showed that both inhibitions disturb pericyte adherence to endothelial cells, a
$80 \%$ after injection of BMCs in Notch-inhibited samples in comparison with injection of BMCs in PBS $(p<0.01, n=6)$. Pillar density demonstrated dramatic augmentation by $63 \%$ compared to the Notch inhibition alone and more than $400 \%$ as compared to PBS $(p<0.001, n=6)$

fact reported previously [50, 51]. However, with the ephrinB2/EphB4 inhibition, no stimulation of intussusceptive angiogenesis was observed, contrary to Notch inhibition. In ephrinB2/EphB4 inhibited samples, the extent of vessel leakage was lesser than in GSI-treated samples as well. One of the primary modulators of the reciprocal communication between endothelial cells and pericytes is Angiopoietin-1/Tie-2 signaling pathway [20]. Ang-1 and Tie-2null mice show reduced coverage and detachment of pericytes, leading to destabilized, leakage-susceptible vasculature [52, 53]. A positive regulation for Ang-1/Tie-2 pathway by Notch signaling was described recently [54]. In the current study, we found that only Notch inhibition, but 
not ephrinB2 or EphB4 inhibition, down-regulated Tie-2. This provides a possible mechanistic explanation for the defects of endothelial/pericytes contacts and increased vessel leakage observed after Notch inhibition.

Notch inhibition results in alteration of VEGF receptor status. Recently, it has been shown that VEGFR1 and VEGFR2 reciprocally determine tip cell selection. For the initiation of the sprouting process, the cell needs lower VEGFR1 and higher VEGFR2 levels, where the latter is involved in negative feedback with Notch [4]. It is plausible to expect that with increase in the ratio VEGFR2/ VEGFR1, there will be enhanced sprouting. Here, we demonstrated that with high increase in VEGFR1 and moderate elevation of VEGFR2 (increased ratio VEGFR1/ VEGFR2) in the context of Notch inhibition, intussusception was the preponderant angiogenic mode.

It is becoming increasingly clear that intussusception is synchronized by several cytokines. Recent studies have demonstrated that bone marrow-derived endothelial progenitor cells (EPCs) home at the sites of neovascularization in response to tissue-derived or circulating cytokines. One of the key chemokine players in developmental vascularization is the stromal cell-derived factor SDF-1, which by binding to its receptor CXCR4 directs migration of progenitor cells into the appropriate sites.

Stroma-derived factor-1-positive endothelium was found lining the newly formed intraluminal vessels in lobular capillary hemangiomas [55], possibly these were sites of pillar formation. The SDF-1/CXCR4 signaling was found to be regulated in endothelial cells through the Notch ligand DLL4 [56]. Wrag et al. [57] demonstrated that transplantation of rat bone marrow-derived progenitor cells, positive for VEGFR1 and CXCR4, in ischemic hind limbs increased capillary density by a SDF-1-dependent manner, but did not differentiate into vascular structures like endothelial cells or SMCs. The latter authors demonstrated recruitment of progenitor cells to the adventitialmedial border zone of the vessels. It has been observed by others that recruitment of monocytes to ischemic tissues can occur without incorporation or differentiation into vascular lineages, suggesting their important role in neovascularization by some alternative mechanism of angiogenesis [58, 59]. In the present study, we observed upregulation of SDF-1 and CXCR4 after Notch inhibition and down-regulation after EphB4 inhibition, up-regulation being in association with intussusceptive angiogenesis. We suggest that stimulation of intussusception after Notch inhibition could be associated with elevated CXCR4/SDF1 expression. The latter factors are most probably essential for the recruitment of mononuclear cells, participating in the formation of pillars.

In conclusion, the recently published data indicated that in the fronts of vessel invasion, inhibition of Notch results in extensive formation of capillary sprouts. Our results demonstrated that the same Notch inhibition within already existing vascular beds (behind the sprouting fronts) induced intussusceptive angiogenesis. The latter is associated with extravasation of mononuclear cells plausibly of bone marrow origin, which participate in formation of the intraluminal endothelial pillars. The vascular pattern observed indicated that intussusceptive angiogenesis is most likely "locked" in the "on" position after Notch inhibition resulting in repetitive pillar formation. The induced intussusception is complementary to excessive sprouting at the front of vessel invasion and both types of angiogenesis contributed to formation of a dense and primitive vascular plexus without concomitant vascular remodeling or maturation. The effect of Notch inhibitioninduced intussusceptive angiogenesis is not mediated by ephrinB2/EphB4 signaling, but rather by chemokine signaling. The results obtained in the current study have potential implications on future treatment strategies of angiogenesis related diseases such as carcinogenesis, retinopathy and macular degeneration, among others.

Acknowledgments We are very grateful to Regula Buergy, Werner Graber, Jeannine Wagner, Barbara Krieger, Christoph Lehmann, and Brigitte Scolari for the wonderful laboratory work and technical support! This work is supported by the Swiss National Foundation Grant Nr: 31003A_135740.

\section{References}

1. Ribatti D, Crivellato E (2012) "Sprouting angiogenesis", a reappraisal. Dev Biol 372(2):157-165

2. Djonov V, Schmid M, Tschanz SA, Burri PH (2000) Intussusceptive angiogenesis: its role in embryonic vascular network formation. Circ Res 86(3):286-292

3. Djonov V, Baum O, Burri PH (2003) Vascular remodeling by intussusceptive angiogenesis. Cell Tissue Res 314(1):107-117

4. Jakobsson L, Franco CA, Bentley K, Collins RT, Ponsioen B, Aspalter IM, Rosewell I, Busse M, Thurston G, Medvinsky A, Schulte-Merker S, Gerhardt H (2010) Endothelial cells dynamically compete for the tip cell position during angiogenic sprouting. Nat Cell Biol 12(10):943-953

5. Makanya AN, Hlushchuk R, Djonov VG (2009) Intussusceptive angiogenesis and its role in vascular morphogenesis, patterning, and remodeling. Angiogenesis 12(2):113-123

6. Styp-Rekowska B, Hlushchuk R, Pries AR, Djonov V (2011) Intussusceptive angiogenesis: pillars against the blood flow. Acta Physiol (Oxf) 202(3):213-223

7. Dill MT, Rothweiler S, Djonov V, Hlushchuk R, Tornillo L, Terracciano L, Meili-Butz S, Radtke F, Heim MH, Semela D (2012) Disruption of Notch1 induces vascular remodeling, intussusceptive angiogenesis, and angiosarcomas in livers of mice. Gastroenterology 142(4):967-977

8. Baum O, Suter F, Gerber B, Tschanz SA, Buergy R, Blank F, Hlushchuk R, Djonov V (2010) VEGF-A promotes intussusceptive angiogenesis in the developing chicken chorioallantoic membrane. Microcirculation 17(6):447-457 
9. Konerding MA, Gibney BC, Houdek JP, Chamoto K, Ackermann M, Lee GS, Lin M, Tsuda A, Mentzer SJ (2012) Spatial dependence of alveolar angiogenesis in post-pneumonectomy lung growth. Angiogenesis 15(1):23-32

10. Schwanbeck R, Martini S, Bernoth K, Just U (2011) The Notch signaling pathway: molecular basis of cell context dependency. Eur J Cell Biol 90(6-7):572-581

11. High FA, Zhang M, Proweller A, Tu L, Parmacek MS, Pear WS, Epstein JA (2007) An essential role for Notch in neural crest during cardiovascular development and smooth muscle differentiation. J Clin Invest 117(2):353-363

12. Napp LC, Augustynik M, Paesler F, Krishnasamy K, Woiterski J, Limbourg A, Bauersachs J, Drexler H, Le NF, Limbourg FP (2012) Extrinsic Notch ligand delta-like 1 regulates tip cell selection and vascular branching morphogenesis. Circ Res 110(4):530-535

13. Tammela T, Zarkada G, Nurmi H, Jakobsson L, Heinolainen K, Tvorogov D, Zheng W, Franco CA, Murtomaki A, Aranda E, Miura N, Yla-Herttuala S, Fruttiger M, Makinen T, Eichmann A, Pollard JW, Gerhardt H, Alitalo K (2011) VEGFR-3 controls tip to stalk conversion at vessel fusion sites by reinforcing Notch signalling. Nat Cell Biol 13(10):1202-1213

14. Suchting S, Freitas C, Le NF, Benedito R, Breant C, Duarte A, Eichmann A (2007) The Notch ligand delta-like 4 negatively regulates endothelial tip cell formation and vessel branching. Proc Natl Acad Sci USA 104(9):3225-3230

15. Roca C, Adams RH (2007) Regulation of vascular morphogenesis by Notch signaling. Genes Dev 21(20):2511-2524

16. Corada M, Nyquist D, Orsenigo F, Caprini A, Giampietro C, Taketo MM, Iruela-Arispe ML, Adams RH, Dejana E (2010) The Wnt/beta-catenin pathway modulates vascular remodeling and specification by upregulating Dll4/Notch signaling. Dev Cell 18(6):938-949

17. MacGrogan D, Nus M, de la Pompa JL (2010) Notch signaling in cardiac development and disease. Curr Top Dev Biol 92:333-365

18. Gridley T (2010) Notch signaling in the vasculature. Curr Top Dev Biol 92:277-309

19. Lobov IB, Cheung E, Wudali R, Cao J, Halasz G, Wei Y, Economides A, Lin HC, Papadopoulos N, Yancopoulos GD, Wiegand SJ (2011) The Dll4/Notch pathway controls postangiogenic blood vessel remodeling and regression by modulating vasoconstriction and blood flow. Blood 117(24):6728-6737

20. Armulik A, Abramsson A, Betsholtz C (2005) Endothelial/pericyte interactions. Circ Res 97(6):512-523

21. Sainson RC, Harris AL (2008) Regulation of angiogenesis by homotypic and heterotypic notch signalling in endothelial cells and pericytes: from basic research to potential therapies. Angiogenesis 11(1):41-51

22. Scheppke L, Murphy EA, Zarpellon A, Hofmann JJ, Merkulova A, Shields DJ, Weis SM, Byzova TV, Ruggeri ZM, Iruela-Arispe ML, Cheresh DA (2012) Notch promotes vascular maturation by inducing integrin-mediated smooth muscle cell adhesion to the endothelial basement membrane. Blood 119(9):2149-2158

23. Liu H, Kennard S, Lilly B (2009) NOTCH3 expression is induced in mural cells through an autoregulatory loop that requires endothelial-expressed JAGGED1. Circ Res 104(4):466-475

24. Egea J, Klein R (2007) Bidirectional Eph-ephrin signaling during axon guidance. Trends Cell Biol 17(5):230-238

25. Himanen JP, Saha N, Nikolov DB (2007) Cell-cell signaling via Eph receptors and ephrins. Curr Opin Cell Biol 19(5):534-542

26. Masumura T, Yamamoto K, Shimizu N, Obi S, Ando J (2009) Shear stress increases expression of the arterial endothelial marker ephrinB2 in murine ES cells via the VEGF-Notch signaling pathways. Arterioscler Thromb Vasc Biol 29(12):2125-2131

27. Sato Y, Watanabe T, Saito D, Takahashi T, Yoshida S, Kohyama J, Ohata E, Okano H, Takahashi Y (2008) Notch mediates the segmental specification of angioblasts in somites and their directed migration toward the dorsal aorta in avian embryos. Dev Cell 14(6):890-901

28. Krebs LT, Starling C, Chervonsky AV, Gridley T (2010) Notch1 activation in mice causes arteriovenous malformations phenocopied by ephrinB2 and EphB4 mutants. Genesis 48(3):146-150

29. Hellstrom M, Phng LK, Hofmann JJ, Wallgard E, Coultas L, Lindblom P, Alva J, Nilsson AK, Karlsson L, Gaiano N, Yoon K, Rossant J, Iruela-Arispe ML, Kalen M, Gerhardt H, Betsholtz C (2007) Dl14 signalling through Notch1 regulates formation of tip cells during angiogenesis. Nature 445(7129):776-780

30. Noguera-Troise I, Daly C, Papadopoulos NJ, Coetzee S, Boland P, Gale NW, Lin HC, Yancopoulos GD, Thurston G (2007) Blockade of Dll4 inhibits tumour growth by promoting nonproductive angiogenesis. Novartis Found Symp 283:106-120

31. Ridgway J, Zhang G, Wu Y, Stawicki S, Liang WC, Chanthery Y, Kowalski J, Watts RJ, Callahan C, Kasman I, Singh M, Chien M, Tan C, Hongo JA, de Sauvage F, Plowman G, Yan M (2006) Inhibition of Dll4 signalling inhibits tumour growth by deregulating angiogenesis. Nature 444(7122):1083-1087

32. Al Haj ZA, Oikawa A, Bazan-Peregrino M, Meloni M, Emanueli C, Madeddu P (2010) Inhibition of delta-like-4-mediated signaling impairs reparative angiogenesis after ischemia. Circ Res 107(2):283-293

33. Benedito R, Rocha SF, Woeste M, Zamykal M, Radtke F, Casanovas O, Duarte A, Pytowski B, Adams RH (2012) Notchdependent VEGFR3 upregulation allows angiogenesis without VEGF-VEGFR2 signalling. Nature 484(7392):110-114

34. Wnuk M, Hlushchuk R, Janot M, Tuffin G, Martiny-Baron G, Holzer P, Imbach-Weese P, Djonov V, Huynh-Do U (2012) Podocyte EphB4 signaling helps recovery from glomerular injury. Kidney Int 81(12):1212-1225

35. Djonov VG, Kurz H, Burri PH (2002) Optimality in the developing vascular system: branching remodeling by means of intussusception as an efficient adaptation mechanism. Dev Dyn 224:391-402

36. Jenkins DW, Ross S, Veldman-Jones M, Foltz IN, Clavette BC, Manchulenko K, Eberlein C, Kendrew J, Petteruti P, Cho S, Damschroder M, Peng L, Baker D, Smith NR, Weir HM, Blakey DC, Bedian V, Barry ST (2012) MEDI0639: a novel therapeutic antibody targeting Dl14 modulates endothelial cell function and angiogenesis in vivo. Mol Cancer Ther 11(8):1650-1660

37. Thurston G, Noguera-Troise I, Yancopoulos GD (2007) The delta paradox: DLL4 blockade leads to more tumour vessels but less tumour growth. Nat Rev Cancer 7(5):327-331

38. Kalen M, Heikura T, Karvinen H, Nitzsche A, Weber H, Esser N, Yla-Herttuala S, Hellstrom M (2011) Gamma-secretase inhibitor treatment promotes VEGF-A-driven blood vessel growth and vascular leakage but disrupts neovascular perfusion. PLoS ONE 6(4):e18709

39. Larrivee B, Prahst C, Gordon E, Del TR, Mathivet T, Duarte A, Simons M, Eichmann A (2012) ALK1 signaling inhibits angiogenesis by cooperating with the Notch pathway. Dev Cell 22(3): 489-500

40. Hlushchuk R, Riesterer O, Baum O, Wood J, Gruber G, Pruschy M, Djonov V (2008) Tumor recovery by angiogenic switch from sprouting to intussusceptive angiogenesis after treatment with PTK787/ZK222584 or ionizing radiation. Am J Pathol 173(4): $1173-1185$

41. Wnuk M, Hlushchuk R, Tuffin G, Huynh-Do U, Djonov V (2011) The effects of PTK787/ZK222584, an inhibitor of VEGFR and PDGFRbeta pathways, on intussusceptive angiogenesis and glomerular recovery from Thy1.1 nephritis. Am J Pathol 178(4): 1899-1912

42. Kucia M, Reca R, Campbell FR, Zuba-Surma E, Majka M, Ratajczak J, Ratajczak MZ (2006) A population of very small 
embryonic-like (VSEL) CXCR4(+)SSEA-1(+)Oct-4+ stem cells identified in adult bone marrow. Leukemia 20(5):857-869

43. Usui F, Yamamoto Y, Nakamura Y, Ono T, Kagami H (2009) Novel system for degeneration of blood vessels by UV irradiation and subsequent regeneration using chick bone marrow cells. Cells Tissues Organs 189(5):348-355

44. Lorusso G, Ruegg C (2008) The tumor microenvironment and its contribution to tumor evolution toward metastasis. Histochem Cell Biol 130(6):1091-1103

45. Coffelt SB, Lewis CE, Naldini L, Brown JM, Ferrara N, De PM (2010) Elusive identities and overlapping phenotypes of proangiogenic myeloid cells in tumors. Am J Pathol 176(4):1564-1576

46. Camelo S, Raoul W, Lavalette S, Calippe B, Cristofaro B, Levy O, Houssier M, Sulpice E, Jonet L, Klein C, Devevre E, Thuret G, Duarte A, Eichmann A, Leconte L, Guillonneau X, Sennlaub F (2012) Delta-like 4 inhibits choroidal neovascularization despite opposing effects on vascular endothelium and macrophages. Angiogenesis 15(4):609-622

47. Lawson ND, Scheer N, Pham VN, Kim CH, Chitnis AB, Campos-Ortega JA, Weinstein BM (2001) Notch signaling is required for arterial-venous differentiation during embryonic vascular development. Development 128(19):3675-3683

48. Fischer A, Schumacher N, Maier M, Sendtner M, Gessler M (2004) The Notch target genes Hey1 and Hey2 are required for embryonic vascular development. Genes Dev 18(8):901-911

49. Jin S, Hansson EM, Tikka S, Lanner F, Sahlgren C, Farnebo F, Baumann M, Kalimo H, Lendahl U (2008) Notch signaling regulates platelet-derived growth factor receptor-beta expression in vascular smooth muscle cells. Circ Res 102(12):1483-1491

50. Cortina C, Palomo-Ponce S, Iglesias M, Fernandez-Masip JL, Vivancos A, Whissell G, Huma M, Peiro N, Gallego L, Jonkheer S, Davy A, Lloreta J, Sancho E, Batlle E (2007) EphB-ephrin-B interactions suppress colorectal cancer progression by compartmentalizing tumor cells. Nat Genet 39(11):1376-1383
51. Noren NK, Pasquale EB (2007) Paradoxes of the EphB4 receptor in cancer. Cancer Res 67(9):3994-3997

52. Sato TN, Tozawa Y, Deutsch U, Wolburg-Buchholz K, Fujiwara Y, Gendron-Maguire M, Gridley T, Wolburg H, Risau W, Qin Y (1995) Distinct roles of the receptor tyrosine kinases Tie-1 and Tie-2 in blood vessel formation. Nature 376(6535):70-74

53. Suri C, Jones PF, Patan S, Bartunkova S, Maisonpierre PC, Davis S, Sato TN, Yancopoulos GD (1996) Requisite role of angiopoietin-1, a ligand for the TIE2 receptor, during embryonic angiogenesis. Cell 87(7):1171-1180

54. Morrow D, Cullen JP, Cahill PA, Redmond EM (2007) Cyclic strain regulates the Notch/CBF-1 signaling pathway in endothelial cells: role in angiogenic activity. Arterioscler Thromb Vasc Biol 27(6):1289-1296

55. Salvucci O, Yao L, Villalba S, Sajewicz A, Pittaluga S, Tosato G (2002) Regulation of endothelial cell branching morphogenesis by endogenous chemokine stromal-derived factor-1. Blood 99(8): 2703-2711

56. Williams CK, Segarra M, Sierra ML, Sainson RC, Tosato G, Harris AL (2008) Regulation of CXCR4 by the Notch ligand delta-like 4 in endothelial cells. Cancer Res 68(6):1889-1895

57. Wragg A, Mellad JA, Beltran LE, Konoplyannikov M, San H, Boozer S, Deans RJ, Mathur A, Lederman RJ, Kovacic JC, Boehm M (2008) VEGFR1/CXCR4-positive progenitor cells modulate local inflammation and augment tissue perfusion by a SDF-1dependent mechanism. J Mol Med (Berl) 86(11):1221-1232

58. Arras M, Ito WD, Scholz D, Winkler B, Schaper J, Schaper W (1998) Monocyte activation in angiogenesis and collateral growth in the rabbit hindlimb. J Clin Invest 101(1):40-50

59. De PM, Venneri MA, Galli R, Sergi SL, Politi LS, Sampaolesi M, Naldini L (2005) Tie2 identifies a hematopoietic lineage of proangiogenic monocytes required for tumor vessel formation and a mesenchymal population of pericyte progenitors. Cancer Cell $8(3): 211-226$ 